\title{
Importance of systemic mediastinal lymphadenectomy in exact staging of bronchogenic carcinoma
}

\author{
Hytych V, Taskova A, Horazdovsky P, Konopa Z, Demes R, Cermak J, Vrabcova A, \\ Hoferka P, Pohnan R
}

Department of Thoracic Surgery, Thomayer's Hospital, Prague, Czech Republic. vladislav.hytych@ftn.cz

\begin{abstract}
Background: Constituent part of radical lung resection for lung cancer is a dissection of mediastinal lymph nodes. Lymphadenectomy is a standard procedure in an assessment of clinical stage of the disease. The aim of the study was to map metastasizing of bronchogenic non-small cell lung carcinoma into homolateral mediastinal lymph nodes and to assess the importance of mediastinal lymphadenectomy for exact staging and survival. Methods: Study of 31patients with lung resection and systematic mediastinal lymphadenectomy operated from August 2004 to January 2007, with pre-operative stage la to Ilb (TNM classification) - according to CT without mediastinal lymph nodes invasion and with positive histological finding after systematic mediastinal lymphadenectomy.

Results: Tumors in right upper lobe metastasized in $45.5 \%$ into group 1 nodes (stages N1-N4) and group 3 nodes (stages N7) and in $9 \%$ into group 4 nodes (stages N8-N9). Tumors of the right middle lobe metastasized in $100 \%$ into group 3 nodes (stage N7). Tumors of the right lower lobe metastasized in $87.5 \%$ into group 3 nodes (N7) and in $12.5 \%$ into group 4 nodes (stages N8-N9). Tumors of the left upper lobe metastasized in $9.0 \%$ in group 1 nodes (stages N1-N4), in $82 \%$ into group 2 nodes (stages N5-N6) and in $9.0 \%$ were found skip metastases into group 4 nodes (stages N8-N9). Tumors of the left lower lobe metastasized in $26.7 \%$ in group 4 nodes, $46.6 \%$ into group 3 nodes, in 20,0\% into group 2 nodes and in 6,7\% into group 1 nodes. Conclusion: Systematic mediastinal lymphadenectomy is crucial for determining the stage of the disease according to the TNM classification. Systematic lymphadenectomy is essential for the diagnosis of stage Illa disease and setting of additional therapy that prolongs survival (Ref. 17). Full Text in PDF www.elis.sk. Key words: systematic lymphadenectomy, bronchogenic carcinoma, additional therapy, lung cancer.
\end{abstract}

Lung cancer is one of the most frequent malignant tumors. Paracelsus (in 1420) wrote about a very uncommon disease of coalminers from Kutna Hora. The first one who described lung cancer was K. Rokitansky in 1842 (1).

In total 77541 malignant tumors were reported in Czech Republic in 2008, from these 39299 were in men and 38242 in women. Relative incidence was $768.7 / 100000$ persons in men, $719.3 / 100000$ persons in women and in total $7435 / 100000$ persons. In 2008 in total 27571 people died of malignant tumors, from them were 15333 men and 12238 women; this represents specific mortality of $299.9 / 100000$ persons men, $230.2 / 100000$ persons in women and in total 264.4/100 000 persons (2).

During one year (2008) increased the number of reported cases of malignant tumors in 1365 in total (797 cases in men and 568 cases in women), which means nearly $2 \%$ increase. The increase of relative incidence in all groups was nearly $6 / 100000$ persons.

Department of Thoracic Surgery, Thomayer's Hospital, Prague, Czech Republic

Address for correspondence: V. Hytych, MD, Department of Thoracic Surgery, Thomayer's Hospital, Videnska 800, CZ-140 59 Prague 4, Czech Republic.

Acknowledgement: We would like to thank to our collegues from Department of Pathology and Department of Pulmonary Medicine of Thomayer's Hospital in Prague.
Total mortality increased in 212 deaths, but specific mortality decreased in men to $0.8 / 100000$ persons, in women to $0.7 / 100000$ persons and in total to $0.6 / 100000$ persons (2).

In 2008 were 4693 new malignant lung tumors reported in men, 1834 in women and in total 6527 new diseases ( $2 \%$ increase comparison to 2007). Relative incidence was $91.8 / 100000$ persons in men, $34.5 / 100000$ persons in women and in total $63.15 / 100$ 000 persons. One half of diseases were diagnosed in the clinical stage IV and the maximum of occurrence was the same in men as in women in group aged 60-64. From 1970 the incidence of malignant lung tumors decreased in men and increased in women more then four times (2).

Lung cancer is the most frequent cause of death in men in Czech Republic. In 2008 died 3922 men (25.6\% of all who died from malignant tumors $=1$. place $)$ and 1480 women $(12.1 \%$ of all women died of malignant tumors $=4 .-5$. place) with the diagnosis of malignant lung disease, in total 5402 diseased. Specific mortality was $76.7 / 100000$ population in men, $27.8 / 100000$ population in women and in total it was $52.25 / 100000$ population (2).

From 1999 the total 5-year survival is above $10 \%(2)$.

Essential for the treatment is to determine the histological classification of tumor (typing), malignity degree (grading) and especially to determine precisely the extent of the malignant process (staging) $(3,4,5,6)$. 
$569-572$

Lung tumors are divided into two groups: small cell lung carcinomas (SCLC) and non-small cell lung carcinomas (NSCLC) $(3,7)$.

The aim of this prospective study was:

A) To map metastasizing of bronchogenic non-small cell lung carcinoma into homolateral mediastinal lymph nodes

B) To assess the importance of mediastinal lymphadenectomy for exact staging

C) To assess the importance of mediastinal lymphadenectomy to survival

\section{Methods}

Standardized systematic mediastinal lymphadenectomy was made in all patients with removal of fatty tissue with mediastinal lymph nodes on the same side as the tumor was located.

Description of the procedure: we started with releasing of the pulmonary ligament by a narrow margin of lower lobe and removed the fatty tissue located within oesophagus, vertebral column, lower pulmonary vein, pericardium and diaphragm. Then we continued with dissection into the space within upper margin of lower pulmonary vein, oesophagus, pericardium and both main bronchi up to the point where bronchus for the upper lobe begins.

On the right side we removed fatty tissue with lymph nodes from the upper margin of main bronchus cranially under azygos vein and then up between vena cava superior, trachea and oesophagus up to brachiocephalic vein. On the bottom we isolated aortic arch. The fatty tissue in front of the vertebral column and ventrally of vena cava superior was removed.

On the left side we removed fatty tissue with lymph nodes from aortic window and from the whole space on aortic arch.

The removed fatty tissue with nodes was separated according to the localization and classification into groups of mediastinal nodes N1-N9.

Removed material was placed into the box filled with $10 \%$ formaldehyde solution.

Further processing was done with standardized method. Examined tissue was dehydrated with increasing concentration of alcohol, then transferred into xylene and immersed in hot paraffin. The tissue was cut into slices. With xylene was the wax removed and hydrating with increasing concentration of alcohol followed.

Samples were coloured by hematoxyline and eosine. Then were the samples arranged to examination in microscope.

We included into the study patients who underwent surgery at Surgical Department of Thomayer's Hospital, Prague, from August 2004 to January 2007. Inclusion criteria were: patients with stage Ia to IIb (TNM classification) preoperatively - according to CT without mediastinal lymph nodes invasion, and had positive histological finding after systematic mediastinal lymphadenectomy.

There were in total 31 patients, 21 men $(67.7 \%)$ with average age 65.0 years (49-83 years) and 10 women (32.2\%) with average age 63.5 years ( $47-78$ years).

Malignity in family history was reported in 7 cases (22.6\%), one case of bronchogenic carcinoma. In personal history was malignancy reported in 5 cases $(16.1 \%$ ), and in one case it was bron- chogenic carcinoma. Most frequent comorbidities were ischemic heart disease $(58.1 \%)$, chronic obstructive pulmonary disease $(54.8 \%)$ and hypertension (45.2\%).

In our group of patients right upper lobe tumors metastasized in $45.5 \%$ into group 1 nodes (stages $\mathrm{N} 1-\mathrm{N} 4$ ) and group 3 nodes (stages N7) and in $9 \%$ into group 4 nodes (stages N8-N9).

Tumors of the right middle lobe metastasized in $100 \%$ into group 3 nodes (stage N7).

Tumors of the right lower lobe metastasized in $87.5 \%$ into group 3 nodes (N7) and in $12.5 \%$ into group 4 nodes (stages N8-N9).

Tumors of the left upper lobe metastasized in $9.0 \%$ in group 1 nodes (stages N1-N4), in $82 \%$ into group 2 nodes (stages N5N6) and in $9.0 \%$ we found skip metastases into group 4 nodes (stages N8-N9).

Tumors of the left lower lobe metastasized in $26.7 \%$ in group 4 nodes, $46.6 \%$ into group 3 nodes, in $20.0 \%$ into group 2 nodes and in $6,7 \%$ into group 1 nodes.

ICU care after surgery lasted from 1 to 61 days. One patient died of severe bilateral pneumonia. Thoracic drainage was removed average 4.6 days (1-11 days). Total time of hospitalization was from 7 to 63 days, average 15.3 days.

Postoperative complications occurred in 10 cases (32.3\%). Most frequent were pneumonia and atelectasis (both in 3 cases), and these patients underwent bronchoscopy with suction. In one case reoperation for haemothorax was performed (preoperatively unrecognized thrombocytopathy).

Postoperative chemotherapy underwent 16 patients (51.6\%). These patients were treated by combination of cisplatin and navelbine. All the patients suffered from minor side effects of chemotherapy, in 4 cases we found severe pancytopenia.

12 patients $(38.7 \%)$ were treated by postoperative radiotherapy.

All the patients suffered from minor side effects of actinotherapy and 8 of them suffered from severe dysphagia and 3 patients had to interrupt the treatment because of generalization of cancer.

5 patients had adjuvant chemoradiotherapy.

Average survival of patients in our study is 1082.7 days. Most frequent cause of death was generalisation of lung carcinoma and/ or its complications. One patient died due to pulmonary embolism and another died due to diffuse peritonitis after perforation of duodenal ulcer.

\section{Discussion}

A) Mapping metastazing of bronchogenic non-small cell lung carcinoma into homolateral mediastinal lymph nodes

Total number of examined patients with non-small cell lung cancer was 31 and these fulfilled the preoperative criterion of negative mediastinal nodes in stage Ia and IIb of the TNM classification.

In total 713 mediastinal lymph nodes were dissected in average 23.3 nodes per patient. In 87 lymph nodes metastases were detected, representing $12.2 \%$ of all collected nodes. On the average in every patient were detected 2.8 lymph nodes with metastases. Tumors of the right upper lobe metastasized in $47.7 \%$ into group 
1 nodes (stages N1-N4) and group 3 nodes (stage N7) and $4.6 \%$ were retrograde metastases into group 4 nodes (stages N8-N9).

Tumors of the right middle lobe metastasized in $100 \%$ into group 3 nodes (stage N7).

Tumors of the right lower lobe metastasized in $16.6 \%$ into group 1, in $77.1 \%$ into group 3 nodes and in $6.3 \%$ into group 4 nodes.

In tumors of the left upper lobe were retrograde metastases detected in $17.0 \%$ in group 1 nodes, in $57.6 \%$ into group 2 nodes, in $12.5 \%$ into group 3 nodes and in $12.9 \%$ into group 4 nodes.

Tumors of the left lower lobe metastasized in $15.1 \%$ into group 1 nodes, $26.7 \%$ into group 2 nodes, $38.1 \%$ into group 3 nodes and $25.1 \%$ into group 4 nodes.

B) Assessing the importance of mediastinal lymphadenectomy for exact staging

In our group of patients no-one had enlarged lymph nodes on CT examination. The nodes were not larger then $12 \mathrm{~mm}$. Mediastinal lymph nodes were classified as N2 0 based on the TNM classification.

If it would be preferred providing sampling in the patients $(8$, $9,10,11,12$ ), according to CT scans, it would not be necessary to remove any nodes, because there were displayed no enlarged nodes. During surgery were found no enlarged nodes. In our case, when 23.3 nodes were removed, the patients would have no chance to be diagnosed and classified correctly according to the TNM classification (there would be an incorrect classification as stage Ia to IIb).

Lung Cancer Study Group recommends to examine one lymph node from each group in dependence on localization of primary tumor and the lymphatic drainage. According to these recommendations six negative nodes are sufficient to confirm stage N0. And so in this case the surgeon should remove six lymph nodes by random choice from upper and middle or middle and lower group. In right and left upper lobe from group 1 stages N1-N4, group 3 stage N7 and on the left side also from group 2 stages N5-N6. There would be skipped retrograde metastases from group 4 . In our study tumors from both upper lobes metastasized into group 4 in $9 \%$.

If on the average 23.3 lymph nodes were removed during systematic mediastinal lymphadenectomy, in case of sampling would be four times lower efficiency. Instead of 31 patients with metastases in nodes to stages N1-N7, would be affected homolateral nodes verified only in 9 patients. It represents only $25.7 \%$ !

In tumors of middle lobe and sampling examination of stages N1N7 could be the result the same, from 24 examined nodes 3 of them would be positive. And so in 6 removed nodes positivity is $0.75 \%$.

In right and left lower lobe we found $25 \%$ probability of verifying metastases in group 1 .

If the patients would underwent systematic sampling $(8,9$, $13,14)$ the probability of correct diagnosis of mediastinal nodes would be 50-75\%. All lymph nodes from all groups and stages would be removed. The fatty tissue would not be removed and the hidden lymph nodes would remain.

Systematic mediastinal lymphadenectomy with removal of all lymph nodes and fatty tissue enabled to determine affection of homolateral lymph nodes and to determine exact staging of lung disease. The result of $12.2 \%$ found positive lymph nodes from all 713 removed nodes, means that leaving even only single positive lymph node definitely affects staging, treatment, prognosis and survival of patients.

C) Assessing the importance of mediastinal lymphadenectomy to patients' survival

There were 28 smokers $(90.3 \%)$ in our group and they smoked in average 36.9 years (from 12 to 55 years) and smoked out on average 283110 cigarettes (43 800-730 000). Eight smokers gived up smoking $(25.8 \%)$ and did not smoke in average 9.25 years (1 to 28 years).

In 4 patients $(12.9 \%)$ we found work risk (founder, welder, work with asbestos, work in enamel works).

The period from diagnosis and time when the patients in our study underwent surgery varied from 10 to 118 days. Average time was 30.7 days.

The most frequent localization of the tumor was the left upper lobe in $32.3 \%$ (10 patients), followed by left lower lobe in $22.6 \%$ (7 patients), in right lower lobe also $22.6 \%$ (7 patients), $16.1 \%$ (5 patients) in right upper lobe and $6.4 \%$ (2 patient) in right middle lobe.

Average size of tumor was $35.6 \mathrm{~mm}$ (17.4-48.2).

$35.4 \%$ (11 patients) had enlarged and affected lymph nodes $\mathrm{N} 1$ in lung hilus on CT scanns and no patient had preoperatively diagnosed affection of lymph nodes N2 and N3. Due to this was the clinical stage classified according to the TNM classification as follows: $32.3 \%$ (10 patients) stage Ia, $25.1 \%$ (8 patients) stage Ib, $32.3 \%$ (10 patients) stage IIa, $9.6 \%$ (3 patients) stage IIb.

Bronchoscopic examination showed pathologies in $38.7 \%$ (12 patients), from this 7x stenosis of subsegmental bronchus and $5 \mathrm{x}$ granulation tissue. According to the cytological examination suspection of non-small cell lung carcinoma was expressed in $45.2 \%$ (14 patients). Histological examination verified diagnosis of lung cancer in $42.8 \%$ (6 patients) from cytological examination suspected.

Functional examination of the lungs confirmed the possibility to perform lung resection. Average figure for vital capacity (VC) was $78.3 \%$ and $75.0 \%$ for forced expiratory volume FEV1. Figure of $\mathrm{pO}_{2}$ was in average 10.2.

There were provided 25 lobectomies and 6 pneumonectomies. In one patient was left upper lobectomy combined with resection of pulmonary artery due to its intraoperative rupture.

Histological examination described squamous cell carcinoma in $52 \%$ (16 patients), adenocarcinoma in $16.1 \%$ (5 patients), bronchioalveolar carinoma in $9.6 \%$ (3 patients), neuroendocrine carinoma in $9.6 \%$ ( 3 patients), large cell carcinoma in $9.6 \%$ (3patients) and adenosquamous carcinoma in $3.2 \%$ (1 patient).

We took in total 234 nodes in group 1 stages N1-N4, this is 7.5 lymph nodes in average per one patient. We verified metastases in 22 lymph nodes, this is $9.4 \%$ of positive nodes in $22.5 \%$ (7) patients. The average in the whole group was 3.1 nodes with metastases.

In group 2 stages N5-N6 lymph nodes from 17 patients were examined. We took in total 145 nodes, average 8.5 nodes per one 
patient. From these 22 lymph nodes were positive, average 1.3 nodes per one patient. We found $15.2 \%$ positive lymph nodes and in $70.5 \%$ (12 patients) metastases were verified, on average in 1.8 nodes.

Lymph nodes in group 3 stages N7 were taken in total number of 180 , this is 5.8 nodes in average per one patient. We verified 27 affected nodes, this is $15.0 \%$ positive lymph nodes in $51.6 \%(16$ patients) who had on average of 1.7 nodes with metastases.

We took in total 154 nodes in group 4 stages N8-N9 with average 4.9 nodes per one patient. 16 lymph nodes were positive, this is on average 0.51 nodes in one patient. We found $10.4 \%$ positive nodes and in $22.6 \%$ ( 7 patients) were metastases verified on average in 2.2 nodes.

We took in total 713 mediastinal lymph nodes, on average 23.3 nodes in one patient. In 87 lymph nodes were discovered metastases, it represented $12.2 \%$ of all collected nodes. Per one patient was found 2.8 lymph nodes with metastases on average.

If systematic mediastinal lymphadenectomy is essential for assessing of clinical stage of the disease according to theTNM classification, then we have to admit it's essential importance in survival of patients with IIIa clinical stage.

To verify the hypothesis it is necessary to evaluate the survival of patients after surgery, who had precisely defined stage of the disease, in group with further treatment, and in untreated group.

The group without treatment is basically the same as if mediastinal lymphadenectomy was not performed. In this group $22.2 \%$ of patients survived one year and two years but no patient survived more then three years.

In the treated group survived one year as well as two years $72.7 \%$ of patients, $59.1 \%$ survived three years, five years survived $48.5 \%$.

\section{Conclusion}

Constituent part of radical lung resection for lung cancer is a dissection of mediastinal lymph nodes. Lymphadenectomy is a standard procedure in an assessment of clinical stage of the disease. Systematic lymphadenectomy is essential for the diagnosis of stage IIIa disease and setting of additional therapy that prolongs survival, thus lymphadenectomy helps to prolong survival of patients in stage IIIa.

\section{References}

1. Hytych V, Vernerová A, Horažd'ovský P. Včasná diagnostika karcinomu plic. Causa Subita 2006; 9: 261-266.

\section{2. http://www.uzis.cz/publikace/novotvary-2008}

3. U.S. National Institutes of Health, National Cancer Institute: NonSmall Cell Lung Cancer (PDQ): Treatment Health Professional Version 2006. www.cancer.gov.

4. Čapov I, Wechsler J, Jedlička V, Spurný V. Systematická mediastinální lymfadenektomie. Brno: Vydavatelství Masarykovy univerzity, 2000.

5. Černý J et al. Špeciálna chirurgia 3. Chirurgia hrudníka. Martin: Osveta, 1993.

6. Musil J, Petř́ík F, Trefný M. Pneumologie. Praha: Nakladatelství Karolinum, 2005.

7. Brambilla E, Travis WD, Colby TV, Corrin B, Shimosalo Y. The new World Health Organization classifi cation of lung tumours. Eur Respir J 2001; 18: 1059-1068.

8. Klein J. Chirurgie karcinomu plic. Praha: Grada, 2006.

9. Gjara A, Newman N, Gamble GP, Kohman LJ, Graziano SL. Effect of number of lymphnodes sampled on outcome in patients with stage I nonsmall cell lung cancer. J Clin Oncol 2003; 21: 1029-1034.

10. Watanabe S, Asamura H. Lymph node dissection for lung cancer. Significance, Strategy, and Technique. J Thorac Oncol 2009; 5: 652-657.

11. Hytych V, Horažd'ovský P, Vernerová A. Chirurgická léčba plicní rakoviny. Causa Subita 2006; 9: 323-324.

12. Doddoli C, Aragon A, Barlesi F et al. Does the extent of lymph node dissection infl uence outcome in patiens with stage I non-small cell lung cancer? Eur J Cardio-Thorac Surg 2005; 27: 680-685.

13. Mountain CF, Dresler CM. Regional lymph node classifi cation for lung cancer staging. Chest 1997; 111: 1718-1723.

14. Keller SM, Adak S, Wagner $\mathbf{H}$ et al. Mediastinal lymph node dissection improves survival in patiens with stage II and IIIa non-small cell lung cancer. Ann Thorac Surg 2000; 70: 358-366.

15. Lardinois D, De Leyn P, van Schil PE, Rami-Porta R, Waller DA, Passlick B, Zielinski M, Junker K, Redina E, Ris HB, Hasse J, Detterbeck F, Lerut T, Werder W. ESTS guidelines for intraoperative lymph node staging in non-small cell lung cancer. Eur Cardio-Thorac Surg 2006; 30: 787-792.

16. Silverberg SG, Connolly JL, Dabbs D et al. Association of directors of anatomic and surgical pathology. Recommendations for processing and reporting of lymph node specimens submitted for evaluation of metastatic disease. Am J Clin Pathol 2001; 115: 799-801.

17. Hytych V, Horažd'ovský P, Vernerová A et al. Totální mediastinální lymfadenektomie. Ročenka intenzivní medicíny. Praha: Galén, 2006: 40-42.

Received October 13, 2011. Accepted July 20, 2013. 